\title{
Actitudes de una red social de docentes cartageneros con relación al uso de las formas de tratamiento pronominal tú y usted
}

\author{
Attitude to a social network of professors from Cartagena in relation to use of the \\ forms of treatment of pronominal you (formal and informal)
}

Nidia Orozco Camacho ${ }^{1}$ iD

Universidad de San Buenaventura, Cartagena (Colombia)

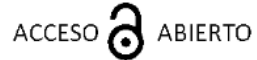

Para citaciones:

Orozco, N. (2020). Actitudes de una red social de docentes cartageneros con relación al uso de las formas de tratamiento pronominal tú y usted. Visitas al Patio, 14(2), 142-158. DOI: $10.32997 /$ RVPvol.14-num.2-2020-2785

Recibido: 17 de febrero de 2020

Aprobado: 17 de abril de 2020

Editor: Silvia Valero. Universidad de Cartagena-Colombia.
Copyright: (C) 2020. Orozco, N. Este es un artículo de acceso abierto, distribuido bajo los términos de la licencia https://creativecommons.org/licenses/by-nc$\underline{\mathrm{sa} / 4.0 /}$ la cual permite el uso sin restricciones, distribución y reproducción en cualquier medio, siempre y cuando el original, el autor $y$ la fuente sean acreditados.

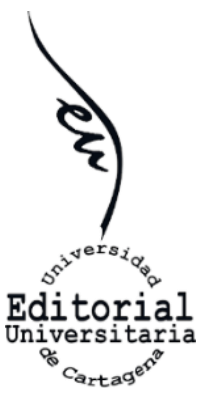

\section{RESUMEN}

Como resultado de la investigación titulada Formas de tratamiento pronominal Tú y Usted en una red social de docentes universitarios de la ciudad de Cartagena de Indias, este documento responde a uno de sus objetivos; evidenciar las actitudes que tienen los hablantes sobre el uso de las formas pronominales de tratamiento. A través de una metodología cualitativa de enfoque descriptivo y explicativo, con estrategias de la etnografía de la comunicación, se hizo un análisis sociopragmático de conversaciones e interpelaciones. se analizó la muestra a partir de la teoría de la valoración de Kaplan (2004) desde la actitud en sus subcategorías de afecto, juicio, sanción social y apreciación sobre las formas de tratamiento. Se concluyó que la percepción sobre tú y usted está generalmente determinada por la confianza que se tenga con el destinatario, con la relación social. Asimismo, desde Escandell (1998, 2006) se revisó la influencia de la distancia social en el uso de los pronominales donde se evidencia que no obedece únicamente a relaciones de jerarquía. Desde la misma percepción de los hablantes, se pudo concluir que el mayor marcador o determinante del uso de una de las dos formas es la Distancia Social

Palabras clave: pragmática; cortesía verbal; formas de tratamiento pronominal; distancia social; conocimiento adquirido; teoría de la valoración.

\begin{abstract}
As a result of the research project "Forms of treatment of pronominal of you, formal and informal, in a social network of university professors in the city of Cartagena de Indias" the present document responds to one of the its objectives; to evidence the attitudes the speakers have towards the use of pronominal forms of treatment. Through a qualitative methodology with a descriptive and explicative approach, with strategies of the ethnography of communication, a socio-pragmatic analysis of the conversations and interpellations was made. The sample was analyzed from the theory of valuation stated by Kaplan (2004) from the attitude in the subcategories of affection, judgment, social sanction and appreciation of the forms of treatment. It was concluded that the perception over you, informal and formal, is generally determined by the level of confidence the receiver has, with the social relationship. Likewise, from Escandell $(1998,2006)$ it was revised the influence of

${ }^{1}$ Profesional en Lingüística y Literatura de la Universidad de Cartagena, Magíster en Lingüística de la Universidad Nacional de Colombia, Doctoranda en Doctorado en Humanidades. Humanismo y Persona de la Universidad de San Buenaventura, Bogotá, investigadora en categoría Asociado y líder del Grupo Interdisciplinario en Educación y Pedagogía (B) y de la Línea de Pensamiento y lenguaje, Docente de la Facultad de Educación Ciencias Humanas y Sociales de la Universidad de San Buenaventura, Cartagena. nidiaestherorozcam@gmail.com
\end{abstract}


the social distance in the use of the pronominals where it is evidenced that it does not only obey to hierarchical relationships. From the conceptions of the speakers, it was concluded that the marker or determiner of the use of one of the two forms is Social Distance.

Key words: Pragmatic; verbal courtesy; forms of pronominal treatment; social distance; acquired knowledge; theory of valuation.

\section{INTRODUCCIÓN}

\section{La categoría de actitud para el estudio de las formas pronominales de tratamiento}

Los hablantes de una lengua no sólo hacen uso de la misma, sino que, así como para determinar qué hablan y cómo lo hacen, tienen en cuenta quién es su destinatario, cuál es el tema y el contexto cognitivo, así mismo, dan valor a lo que usan; asumen actitudes frente a la lengua, emiten juicios de valoración, entre otros. Esto ha llevado a que los estudios en el campo de la Lingüística, la pragmática y otras interdisciplinas no se centren sólo en lengua y habla desde el uso sino también en la evaluación de éstas. De allí que surjan teorías de valoración lingüística como la sustentada por Kaplan (2004) donde se presentan fundamentos sobre la evaluación que consideran las actitudes sobre la lengua.

La valoración es entendida por Kaplan (2004) como "la construcción discursiva de la actitud y de la postura intersubjetiva [...] que incluye todos los usos evaluativos del lenguaje..." (p.58). Esta construcción es la que se evidencia en juicios sobre la misma lengua que se exteriorizan con las realizaciones lingüísticas. Para el caso de esta investigación, los hablantes expresan actitudes frente a una u otra forma pronominal asociada al contexto cognitivo, a la distancia social (estos dos últimos elementos no los expone la teoría de la valoración, pero son justamente articulables para comprender los términos de la valoración en el problema de las formas pronominales de tratamiento).

Los subsistemas de la valoración son: la actitud, el compromiso y la gradación. En este estudio, se trabajó sólo con la actitud que también es abordada por otros autores, además de Kaplan, como: Baker, 1992; Lynn y Fitz, 1987, entre otros. En primera instancia, precisemos qué se entiende por actitud, en general en el campo sociolingüístico, y luego nos concentraremos en la actitud lingüística específicamente desde Kaplan (2004) puesto que ella la trabaja desde el plano pragmático centrado en lo cognitivo.

Para Baker (1992) la actitud "es un constructo hipotético empleado para explicar la dirección y persistencia de la conducta humana" (P.10) Funciona como principio rector de una evacuación del uso de la lengua. La actitud debe inferirse de las expresiones literales que, por medio de juicios, uso de adjetivos, entre otros, se evidencia una evaluación.

Hernández (s.f.) citando a Lynn y Fitz, resalta el concepto y las implicaciones de la actitud entendida como: 
una herramienta útil para observar orden y consistencia en lo que la gente dice, piensa y hace, de modo que, dados ciertos comportamientos, se puedan llevar a cabo predicciones sobre otros comportamientos futuros. Una actitud no es algo que se pueda examinar y medir del mismo modo que las células de la piel o el ritmo de pulsaciones de una persona (29)

Por lo anterior, es justamente desde una exteriorización lingüística o de actos que se expresan juicios de valor ya sea explícita o implícitamente. Por ejemplo, con el uso de adjetivos calificativos, expresiones que evidencian la valoración como por ejemplo decir: "El pronombre tú más que todo en confianza (inf.3m), "cuando hablo utilizo el usted con un determinado tono, que inmediatamente marca la diferencia", te dice: "Ey tú, ven acá", o "fulano, cómo estás, ey"; te trata de determinada manera, que no es la manera apropiada en el momento." (inf. $1 \mathrm{~m}$ ). Con estos ejemplos se puede ver la valoración que dos hablantes tienen frente al tú, para relación de cercanía o familiaridad y el usted para eje de jerarquía y manifestar lejanía o poder.

\section{Metodología}

La estrategia metodológica empleada, se basó en los estudios socios pragmáticos sobre la cortesía. Del fenómeno se analizan patrones de interacción social de una red social de docentes cartageneros donde los roles asumidos por los sujetos determinan el uso de la lengua con relación a las formas de tratamiento. Además, la investigación se inscribe dentro de la lingüística funcional que tiene en cuenta los actos de habla enmarcados en contextos de situación que influyen en el uso de la lengua, y desde este paradigma la estrategia etnográfica es asumida como parte de su método de investigación.

Dentro de la comunidad de habla cartagenera, se tuvo en cuenta una red social de docentes universitarios. Se considera una red puesto que todos los docentes pertenecen a la misma Facultad y aunque algunos tienen formación en diferentes disciplinas, comparten espacios; sala de docentes, asisten regularmente a las mismas reuniones de comité de investigación, comité curricular. Asimismo, cuando se hacen capacitaciones generales coinciden en estas, además comparten otros espacios como la cafetería, y algunos mantienen vínculos personales que les permiten compartir fuera de la Universidad; restaurantes, hogares, reuniones sociales y académicas. Estas relaciones los hacen ser una red que les permite interactuar entre sí y con otros miembros de las redes de cada docente; familia, colegas.

Como la intención del estudio se centra en revisar el fenómeno de las formas de tratamiento en Cartagena, se tuvo en cuenta para una muestra de éste que todos los docentes fueran cartageneros. Este fue uno de los criterios de inclusión y exclusión en la selección de la muestra dado que dentro de la población había docentes en la red general que no eran cartageneros. Teniendo en cuenta la población, 10 docentes para ser analizados constituyó una muestra representativa porque el objeto de análisis fueron las conversaciones e interpelaciones que permiten revisar el uso en otras personas más allá de la muestra misma. Puesto que refirieron sus formas de tratamiento con otros miembros. 10 docentes fueron los informantes, pero éstos suministraron información sobre cómo se daban las formas de tratamiento en las relaciones que tejen con otras personas de su red social. Por ejemplo; se tejen contactos cotidianos con jefes, secretarias, personas del servicio doméstico, en sus 
hogares, de servicios generales de la universidad donde laboran, dependientes, vendedores. Se articulan, así, sus relaciones en el trabajo y fuera de él. Esto no quiere decir que durante la investigación nos trasladáramos a sus otros entornos, sino que, revisando sus cuestionarios y entrevistas, conversaciones, nos hacen referencias a ellas.

Dado que el interés del estudio estuvo centrado en el análisis de si la Distancia Social y el Contexto Cognitivo inciden el uso de los pronombres tú y usted se determinó el sitio teniendo en cuenta los roles que sus integrantes asumen para dar cuenta del fenómeno de las formas de tratamiento, que no sólo está influenciado por variables sociales sino también por lo que hacen los hablantes (Docentes universitarios).

Para la recolección de los datos se asumieron las siguientes técnicas e instrumentos: La grabación de las conversaciones e interpelaciones de la red social en estudio que se complementaron con la observación sistemática y de las entrevistas a los informantes. La observación fue participante dado que la investigadora hace parte de la comunidad estudiada y estuvo involucrada, mesuradamente, en las actividades que realizaban los sujetos estudiados. Resultó una técnica clave puesto que como afirma Duranti (2004) “... no se espera que las generalizaciones sobre las instituciones locales se basen exclusivamente en la información recogida de las palabras de los informantes, sino que está respaldada en todo momento por las propias observaciones que el investigador de campo haga de la conducta real de los individuos." (132) Esta técnica permitió ampliar el análisis de las conversaciones y soportar así, lo concerniente a motivaciones y actitudes sobre las formas de tratamiento.

La encuesta (cuestionario con preguntas cerradas de escogencia dicotómica entre tú y usted, y preguntas abiertas para reforzar las selecciones de una u otra forma)

Para complementación del método se hizo una adecuación del modelo de encuesta propuesto por el grupo PRESEEA, coordinado por Francisco Moreno Fernández, para estudios sobre forma de tratamiento, cuyo objetivo es la recolección de información acerca del tratamiento dado a las personas con las cuales los sujetos de estudio interactúan dependiendo su rol.

Para la validación de la investigación se tuvieron en cuenta los criterios trabajados por la investigación cualitativa en cuanto al principio de triangulación dado que se analizaron los resultados obtenidos de la observación y se revisó la información también desde la perspectiva de los informantes para obtener una visión desde diferentes ángulos.

La entrevista: Se hizo de la forma como lo hacen los antropólogos lingüistas donde no se parte de un cuestionario estructurado, pero estuvo centrada en temas específicos, después de haber leído y revisado las encuestas donde los hablantes evidenciaban los usos de los pronombres en situaciones comunicativas específicas (Duranti,2004:154). Permitió la interacción durante el trabajo de campo y como afirma Duranti(2004): “...la entrevista podría ser un instante decisivo para obtener información cultural de fondo que les permita comprender los intercambios lingüísticos específicos que son objeto de su estudio..." (p. 148) porque se podía dar el caso, y de hecho así ocurrió reiteradamente, que durante la observación no se 
recojan los datos suficientes que se necesitan para el análisis completo del fenómeno. A través de la entrevista pudimos indagar sobre el fenómeno en las relaciones que los hablantes de la red social estudiada entablan con otros que no pueden ser observados.

Para el análisis de los datos fueron seleccionadas muestras del corpus con el fin de hacerlo en función de los objetivos específicos; actitud lingüística, usos, elementos y componentes de la situación comunicativa y en general revisar las categorías de análisis.

\section{Resultados}

Hernández sostiene que las actitudes "son una actividad cognitiva, si bien formulada mediante una actividad social, el cambio en las actitudes tiene lugar lenta y gradualmente, y en función de las necesidades y motivos individuales y de las situaciones sociales como son los ciclos de vida y sus modos”. (p. 31) y muchas veces está influenciada por lo que el contexto ofrece, por las creencias por lo que se nos enseña en casa como lo expresa en la entrevista el informante codificado como $1 \mathrm{~m}$ : "en el hogar uno debe aprender a usar esas formas de tratamiento". Esta afirmación evidencia que las normas de cortesía en las familias determinan el uso de las formas pronominales en las que se insiste en el tratamiento con usted para adultos en lo concerniente a la red de docentes cartageneros.

Para la teoría de la valoración, según Kaplan (2004) parafraseando a White, el uso evaluativo del lenguaje se hace para establecer tres posicionamientos; actitudinal, dialógico e intertextual. En esta investigación, nos centramos en el actitudinal con el cual se indica una valoración positiva o negativa y se relaciona con aprobación o asignación de culpa o responsabilidad frente un objeto, circunstancia situación, lengua (Kaplan, 2004: 59)

La actitud como subsistema de la valoración se puede relacionar con sistemas de valores internos o culturales; es una evaluación intersubjetiva que trasmite valoración positiva o negativa sobre algo, en este caso el uso de una u otra forma de tratamiento, tú y usted, que puede invitar a otro a hacer también su evaluación. Las subcategorías que según Kaplan (2004) la soportan son: el afecto, el juicio y la apreciación.

El afecto está centrado en la evaluación de los fenómenos, el juicio sobre la conducta a tendiendo normas institucionalizadas y la apreciación concentra la evaluación en cuanto procesos, objetos, textos. En esta investigación se realiza el análisis de esta categoría, actitud teniendo en cuenta las expresiones de los docentes sujetos de estudio.

Según Kaplan (2004) la actitud puede ser explícita o implícita. La primera se expresa a través de frases que trasmiten una evaluación positiva o negativa. La implícita es más compleja y depende también de quien interpreta quien debe aportar desde sus creencias y representaciones y lecturas de contexto.

Con relación a las categorías que soportan la actitud Kaplan plantea los siguientes cuadros: 


\begin{tabular}{|l|l|l|}
\hline AFECTO & \multicolumn{2}{|l|}{ Evaluación } \\
\cline { 2 - 3 } Categorías & Ejemplos Positivos & Ejemplos Negativos \\
\hline Felicidad/infelicidad & $\begin{array}{l}\text { Feliz alegre, jubiloso, } \\
\text { optimista }\end{array}$ & $\begin{array}{l}\text { Triste, deprimido, miserable, } \\
\text { angustiado }\end{array}$ \\
\hline Seguridad/inseguridad & $\begin{array}{l}\text { Confiado, seguro, } \\
\text { tranquilo, sereno }\end{array}$ & $\begin{array}{l}\text { Ansioso, preocupado, inseguro, } \\
\text { intranquilo }\end{array}$ \\
\hline Satisfacción/insatisfacción & $\begin{array}{l}\text { Interesado, absorto, } \\
\text { gustar }\end{array}$ & $\begin{array}{l}\text { Cansado, aburrido, exasperado, } \\
\text { odiar }\end{array}$ \\
\hline
\end{tabular}

(Kaplan, 2004, p. 62)

Se pueden usar adjetivos, adverbios que expresen circunstancias, especialmente de modo, procesos (verbos) entre otras categorías gramaticales que evidencien evaluación. El afecto de acuerdo con Kaplan (2004) puede ser autoral o no autoral; el primero es cuando la expresión evidencia la primera persona y la segunda es cuando se expresa en tercera persona. Ejemplo: Autoral: "yo generalmente uso el pronombre usted cuando..." (Inf. 3m) no autoral: "hay momentos en que una persona de menor rango trata como de abusar dentro de la relación (inf. 1m).

El juicio también tiene establecidas sus subcategorías que son; la estima social y la sanción social:

\begin{tabular}{|c|c|c|}
\hline \multicolumn{3}{|l|}{ JUICIO } \\
\hline \multicolumn{3}{|l|}{ ESTIMA SOCIAL } \\
\hline & $\begin{array}{l}\text { Ejemplo } \\
\text { (admiración) }\end{array}$ & $\begin{array}{l}\text { Ejemplo } \\
\text { (crítica sin implicaciones } \\
\text { legales) }\end{array}$ \\
\hline Normalidad & $\begin{array}{l}\text { Corriente, común, } \\
\text { normal, afortunado/a, } \\
\text { moderno/a }\end{array}$ & $\begin{array}{l}\text { Excéntrico/a, } \\
\text { extraño/a, raro/a, } \\
\text { desafortunado/a } \\
\text { anticuado/a }\end{array}$ \\
\hline Capacidad & $\begin{array}{l}\text { Habilidoso, } \\
\text { inteligente, } \\
\text { intuitivo/a, atlético/a, } \\
\text { fuerte }\end{array}$ & $\begin{array}{l}\text { Inhábil, lento/a, } \\
\text { tonto/a, torpe, débil }\end{array}$ \\
\hline Tenacidad & $\begin{array}{l}\text { Heroico/a, valiente, } \\
\text { confiable, infatigable y } \\
\text { perseverante }\end{array}$ & $\begin{array}{l}\text { Cobarde, } \\
\text { apresurado/a, no } \\
\text { confiable, distraído, } \\
\text { perezoso/a }\end{array}$ \\
\hline \multicolumn{3}{|l|}{ SANCIÓN SOCIAL } \\
\hline & Ejemplo positivo & Ejemplo negativo \\
\hline Veracidad & $\begin{array}{l}\text { Sincero/a, honesto/a, } \\
\text { genuino/a, franco/a, } \\
\text { directo/a }\end{array}$ & $\begin{array}{l}\text { Deshonesto/a, } \\
\text { mentiroso/a, } \\
\text { inauténtico/a, } \\
\text { manipulador/a }\end{array}$ \\
\hline Integridad Moral & $\begin{array}{l}\text { Moral, bondadoso/a, } \\
\text { respetuoso/a de la ley, } \\
\text { sensible, justo/a }\end{array}$ & $\begin{array}{l}\text { Inmoral, } \text { malvado/a, } \\
\text { corrupto/a, cruel, } \\
\text { injusto/a }\end{array}$ \\
\hline
\end{tabular}

(Kaplan, 2004, 64)

Kaplan (2004) advierte que los ejemplos no determinan que ese es necesariamente la palabra que debe usarse o que necesariamente expresa ese tipo de juicio, sino que depende en contexto en que se produce y la parte del enunciado en que se encuentre. 
La tercera categoría de la actitud es la apreciación la cual se encuentra ejemplificada en la siguiente tabla:

\begin{tabular}{|c|c|c|}
\hline \multicolumn{3}{|l|}{ APRECIACIÓN } \\
\hline & Positiva & Negativa \\
\hline $\begin{array}{l}\text { REACCIÓN } \\
\text { Impacto }\end{array}$ & $\begin{array}{l}\text { Cautivador/a, llamativo/a, } \\
\text { atractivo/a, agradable, } \\
\text { conmovedor/a. }\end{array}$ & $\begin{array}{l}\text { Aburrido/a, tedioso/a, } \\
\text { ascético/a, pedante y soso/a }\end{array}$ \\
\hline $\begin{array}{l}\text { REACCIÓN } \\
\text { Calidad }\end{array}$ & $\begin{array}{l}\text { Hermoso/a, espléndido/a, } \\
\text { encantador/a. }\end{array}$ & $\begin{array}{ll}\mathrm{Feo} / \mathrm{a}, & \text { repulsivo/a, } \\
\text { repugnante } & \end{array}$ \\
\hline $\begin{array}{l}\text { COMPOSICIÓN } \\
\text { Balance }\end{array}$ & $\begin{array}{l}\text { Balanceado, armonioso/a, } \\
\text { simétrico/a, proporcionado }\end{array}$ & $\begin{array}{l}\text { Desbalanceado/a, } \\
\text { discordante, } \\
\text { desproporcionado/a, } \\
\text { asimétrico }\end{array}$ \\
\hline $\begin{array}{l}\text { COMPOSICIÓN } \\
\text { Complejidad }\end{array}$ & $\begin{array}{l}\text { Simple, } \\
\text { detallado/a, } \\
\text { intrincado/a }\end{array}$ & $\begin{array}{l}\text { Extravagante, monolítico, } \\
\text { simplista, impreciso/a, }\end{array}$ \\
\hline VALUACIÓN & $\begin{array}{l}\text { Profundo/a, innovador, } \\
\text { original, único/a, exigente }\end{array}$ & $\begin{array}{l}\text { Superficial, insignificante, } \\
\text { reaccionario/a, } \\
\text { conservador/a }\end{array}$ \\
\hline
\end{tabular}

(Kaplan, 2004, p. 66)

El afecto es más personalizado que el juicio y la apreciación puesto que estos dos presentan similitudes porque se dirigen a la entidad evaluada más que al sujeto evaluador (Kaplan, 2004, p. 67)

Si bien la teoría de la Valoración es más usada en análisis de discurso, consideramos posible ajustar algunos aspectos a nuestros estudios dado que el objeto de análisis son conversaciones principalmente donde el hablante expone su postura frente al fenómeno estudiado; esto en el caso de la entrevista se profundiza aún más. Algunas de las categorías no son estudiadas a profundidad porque no son pertinentes para el estudio.

La red social de docentes universitarios estudiada participó en la investigación a través de la aplicación del cuestionario adaptado de PRESEEA, la realización de una entrevista y la grabación de conversaciones e interpelaciones entre los mismos miembros. Las técnicas y los instrumentos se aplicaron con la intención, especialmente, de analizar sus formas de tratamiento con relación al tú y al usted, específicamente, pero antes de profundizar en esos resultados se consideró necesario tomar del corpus obtenido información que nos permitiera evidenciar las actitudes de los hablantes sobre el uso de estas formas de tratamiento.

Las concepciones, percepciones, imaginarios y actitudes que los hablantes de una lengua tienen sobre el mismo lenguaje que usan sobre sus producciones, es importante para analizar, en este caso, sus formas de tratamiento. Dependiendo de cómo perciban una forma así determinan su uso; cómo, cuándo y dónde. Por ejemplo; entre los informantes Inf.1m e Inf 5m, existe una marcada diferencia en el uso de tú y usted. Para el primero es indiferente cómo lo traten, de hecho, responde: "me da igual", sin embargo, el segundo considera importante que pronombre usan para tratarlo por lo que dice: “... debido a que soy profesor, no me gusta que los estudiantes me tuteen sin conocerme bien, la verdad no..." Por su parte el Inf. 3m afirma que muchas veces usa el Usted para que le devuelvan ese trato. Las 
percepciones contribuyen al análisis desde el conocimiento adquirido que establece un vínculo más intrínseco, y no expresamente extrínseco como la mayoría de los estudios en cortesía revelan. Pudimos reafirmar que la Distancia social influye en la forma de tratamiento, pero la fuerza que tiene el contexto cognitivo se acrecienta, por lo que con la percepción tenemos un sustento que motiva una u otra forma de tratamiento (Tú o Usted).

Las percepciones más comunes en la red se expresan en las siguientes relaciones dicotómicas, donde para la primera categoría se usaría tú y para la segunda usted: conocido/desconocido, subalterno/superior y cercano/lejano. Veamos algunas expresiones:

"Bueno, yo generalmente uso el pronombre usted cuando sé que la persona es de un rango mayor al mío por lo menos, por ejemplo, si es un jefe o una persona mayor a la cual no conozco, eso para el uso del pronombre usted". (Entrevista personal (entrevista informante 4M).

"El pronombre tú más que todo en confianza, cuando sé que es una persona conocida; un amigo por ejemplo" (informante 4M)

Informante $1 \mathrm{~m}$ :

- “... pues es mejor, cuando no se sabe con quién se está tratando, manejar el usted, en particular yo lo hago."

- "Bueno, dentro de mi experiencia familiar, el tú es la norma, y por lo menos en el caso de mi familia, siempre se maneja hasta para los regaños, decirle "Tú estás haciendo tal cosa"; pero sí conozco personas que manejan indistintamente las dos formas dependiendo del estado de ánimo"

- "Yo siento que la confianza juega un papel importante en el trato, y cuando nos encontramos, o yo en particular, me encuentro con personas, con las que no tengo la suficiente confianza, prefiero tratarla de usted, para mantener, como te he dicho en algún momento, la distancia con la persona, porque de pronto no inspira esa confianza. Nosotros que coloquialmente utilizamos el término "liso", hay gente que es "lisa", y una manera de frenarla es ponerle el usted por delante."

Informante 3F:

- "pero yo pienso que depende del grado de confianza y como del espacio"

Informante $2 \mathrm{f}$

- Yo la veo (refiriéndose a la forma usted) desde el punto de vista de relaciones sociales; distante, o sea, no tengo mucha confianza con ella, esa es como la principal causa, y también puede ser por la edad, aunque puede que tenga confianza, pero si es de edad avanzada, la tendencia es decirle usted.

- Bueno, puede que empiece de pronto tratando a alguien de usted, pero con el tiempo, si ya nos vamos acercando, si ya hay una relación más íntima, más personal, la tendencia es cambiar al tú. Pero tengo en cuenta sobre todo la edad y el tipo de relación que esté estableciendo con la persona. 
- Yo veo eso como bien raro, porque yo creo que uno tiene como que estar definido, si tiene confianza con la persona, el grado de intimidad, todo lo que permita que le digas tú, ya está establecido, porque es como que cambiar de repente de acuerdo; sobre todo que cambies de un minuto a otro, es como falta de definición, de estar segura de algo ¿Cierto? Algo debe haber allí en la relación, algún temor tendrá en un momento dado, no sé, o por apariencia; de pronto, quieran marcar distancia en algunos momentos, para que esa persona no sobrepase los límites.

- Yo creo fundamentalmente que el usted es una marca de distancia, si, de respeto también, o sea las dos; pero principalmente de distancia, y yo no me meto, como dijiste ahora, dentro del grupo de costeños que tutea a todo el mundo, yo no. La tendencia mía no es tutear, como te digo, la gente así que..., aunque sea más joven si veo que es como de un estrato inferior al mío, le quiero marcar la distancia; para que no se tome el abuso de hablarme de una manera que a mí no me gusta, yo le digo usted, le digo tú a la gente que, aunque tenga un cargo superior, es más joven que yo.

- Informante 2M: Bueno, siempre he considerado que ese es un trato respetuoso, ¿no?, (refiriéndose al usted) de mucho más respeto y consideración con las personas, al menos que ellos les guste que los trate con más confianza, pero siempre le trato que más prevalece en mí es usted, al dirigirme.

- en términos generales uno siempre se refiere a usted, el tratamiento que uno le da a las personas de usted, al menos pues que ya haya un..., hay personas a las que les gusta ¿no?, de pronto por su idiosincrasia, hasta lo ven como que son más extrovertidas las personas cuando las tutean, hay personas que consideran eso, yo me he dado cuenta, he observado; y en cambio cuando uno se habla mucho de usted, usted, sienten como si hubiese una barrera por el medio, se aíslan, eso depende de la idiosincrasia de las personas; por lo menos, a mí siempre me han enseñado, yo pienso que eso es del hogar, ¿no? que uno siempre se dirige a las personas con usted, "Hágame el favor"... Hay personas que van a una tienda y dicen "mira despáchame ahí..." y se refieren en esa forma ¿no?; mientras que hay unas que dicen: "mira me puede hacer el favor y me despacha esto y esto"; o sea, eso es un trato que uno aprende en el hogar; definitivamente, se oye de los papás y de los tíos, uno desde pela 'o va aprendiendo esa forma de tratar a las personas.

\section{Informante $3 \mathrm{~m}$}

- básicamente es porque encontramos que el cartagenero tiene una cultura totalmente abierta, es muy abierto y cree, pienso yo, que en el momento que tutea está demostrando que existe una relación ya directa con el interlocutor. De esa forma estaríamos mirando la pregunta; o sea, estaríamos diciendo que la confianza, es muy confianzudo, y en esa confianzuda, incluso, se puede llegar como a una falta de respeto, cuando tratan de tú. Por ejemplo, hay una expresión en los vendedores, el vendedor se queda mirando a uno y le dice "habla"; o sea, como si fuera...Que va a hablar uno, o sea, es un tipo de cultura, en la cual, para ofrecer un producto, le faltan el respeto a uno; esa es una falta de respeto. "Habla", que voy a hablar, sí. Entonces, lo correcto es que se dirija, en otros términos. 
- $\quad$ En otras partes del país, el vendedor es muy discreto con el cliente, con el posible cliente, aquí no. Aquí el vendedor aborda a uno; el cartagenero básicamente, aborda a uno y va directo, va tuteándolo, y en esa medida algunas personas se sienten lesionadas, como una falta de respeto. Yo en ese aspecto, me he acostumbrado ya a la cultura y entiendo. Por ejemplo, un taxista, yo cojo un taxi los martes, cuando estoy con pico y placa, y yo trato de usted, ¿me entiendes?; o sea, para poner inmediatamente como una distancia, entre el pasajero y el taxista, quien está ofreciendo el servicio.

- En ese aspecto yo soy muy respetuoso, básicamente, lo hago siempre tratando de usted a las personas desconocidas.

Informante $3 \mathrm{~F}$.

- Bueno, generalmente, trato, sobre todo, de tú; es una manera siempre, de entrar en confianza con la gente, independientemente del rango, el estatus, el romper el hielo. No sé si tenga que ver con mi personalidad o con una manera de ver el mundo; pero prefiero siempre el tú al usted, sobretodo en el contexto costeño, caribeño.

Los fragmentos son tomados de algunas de las entrevistas que sirven como fundamento para las actitudes sobre el uso de las formas pronominales de tratamiento. En general, los 10 informantes que sirvieron como base de la red social, tienen la percepción de que el tú está relacionado con la confianza, la cercanía que se tenga con el destinatario, con la relación social.

Con base en las categorías de la teoría de la valoración, presentadas por Kaplan (2004) se presentan ejemplos tomados de las conversaciones de la red social, sus respuestas a la entrevista y se ubican las frases dentro de la categoría correspondiente:

\begin{tabular}{|c|c|c|}
\hline \multicolumn{3}{|c|}{ AFECTO SOBRE EL USO DE LAS FORMAS DE TRATAMIENTO } \\
\hline \multirow[t]{2}{*}{ Categorías } & \multicolumn{2}{|l|}{ Evaluación Tú/usted } \\
\hline & Ejemplos Positivos & Ejemplos Negativos \\
\hline Felicidad/infelicidad & $\begin{array}{l}\text { Me gustó que me dijeran } \\
\text { tú (Inf. 6f) }\end{array}$ & \\
\hline Seguridad/inseguridad & $\begin{array}{l}\text { yo creo que es que esas } \\
\text { personas no están como } \\
\text { que todavía muy seguras } \\
\text { del tratamiento; } \\
\text { personas que antes me } \\
\text { decían usted, que } \\
\text { empiezan a decirme tú. } \\
\text { (Inf. 2f) }\end{array}$ & $\begin{array}{l}\text { no quiero que se tomen } \\
\text { el derecho de también } \\
\text { tutearme (Inf. } 1 \mathrm{~m} \text { ) }\end{array}$ \\
\hline Satisfacción/insatisfacción & $\begin{array}{l}\text { Para mi caso es } \\
\text { indiferente la forma en } \\
\text { que me tratan, } \\
\text { me gustó que me dijeran } \\
\text { tú (Inf. } 5 \mathrm{f} \text { ) }\end{array}$ & $\begin{array}{l}\text { al principio } \underline{\text { me }} \\
\text { incomodó, con ella, no } \\
\text { sé, como es una niña tan } \\
\underline{\text { confianzuda (Inf. } 2 \mathrm{f})}\end{array}$ \\
\hline
\end{tabular}

Tabla 1. Fuente: Investigadora 


\begin{tabular}{|c|c|c|}
\hline \multicolumn{3}{|c|}{ ESTIMA SOCIAL } \\
\hline & Ejemplo positivo (admiración) & $\begin{array}{l}\text { Ejemplo negativo (crítica sin } \\
\text { implicaciones legales) }\end{array}$ \\
\hline Normalidad & 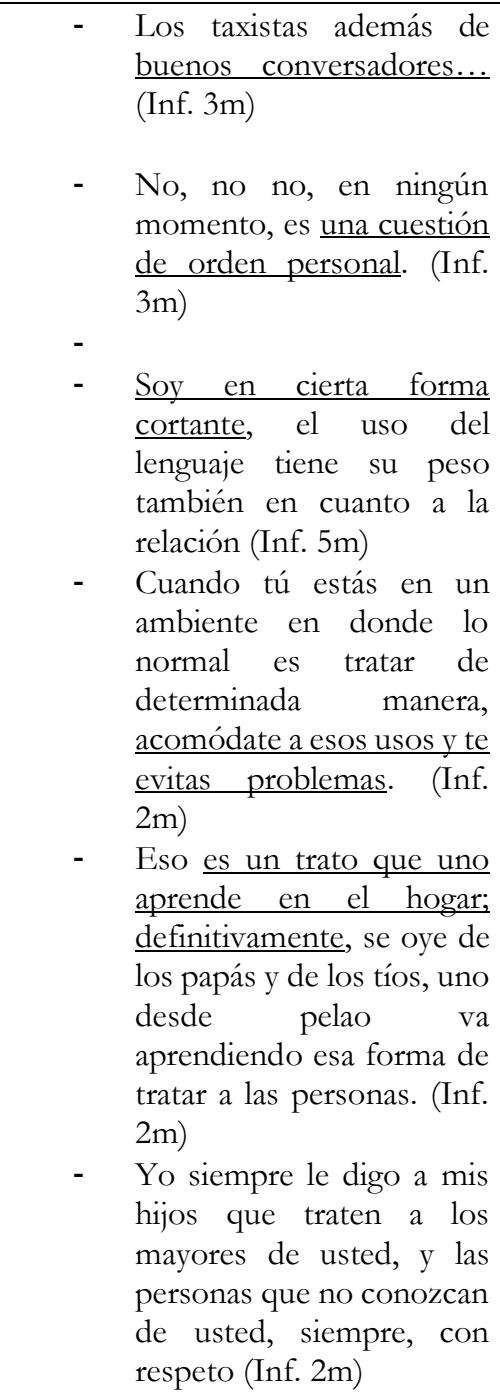 & 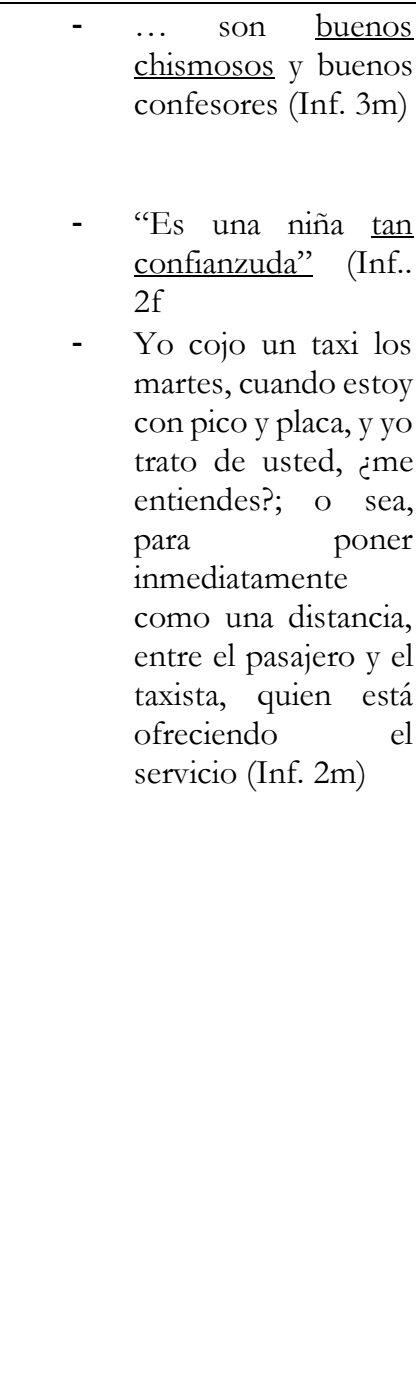 \\
\hline & $\begin{array}{l}\text { - Eso es algo que está, como } \\
\text { digo, ya dentro de la } \\
\text { persona; ya eso es una } \\
\text { costumbre innata ya de las } \\
\text { cosas del hogar, todo } \\
\text { viene del hogar; hasta todo } \\
\text { lo que es la mentalidad, } \\
\text { inclusive (Inf. } 3 \mathrm{~m} \text { ) }\end{array}$ & \\
\hline Capacidad & $\begin{array}{l}\text { - Yo creo } \\
\text { fundamentalmente que el } \\
\text { usted es una marca de } \\
\text { distancia, si, de respeto } \\
\text { también, o sea las dos; }\end{array}$ & \\
\hline
\end{tabular}




\begin{tabular}{|c|c|c|}
\hline & $\begin{array}{l}\text { pero sobretodo de } \\
\text { distancia. (inf. 1m) } \\
\text { Lo trato de usted, } \\
\text { precisamente para } \\
\text { mantener la distancia (Inf. } \\
\text { 3m) } \\
\text { Sé reconocer dentro de la } \\
\text { relación social cuando se } \\
\text { debe utilizar el usted. } \\
\text { - Generalmente yo siempre } \\
\text { les hablo con cariño a } \\
\text { ellos. } \\
\text { En ese aspecto yo soy muy } \\
\text { respetuoso, básicamente, } \\
\text { lo hago siempre tratando } \\
\text { de usted a las personas } \\
\text { desconocidas (Inf. } 2 \text { m) }\end{array}$ & \\
\hline Tenacidad & 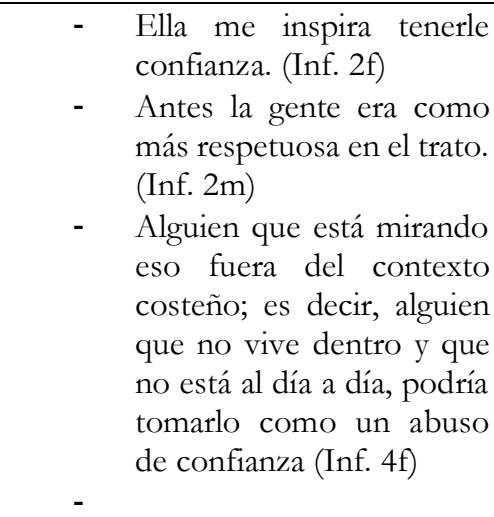 & 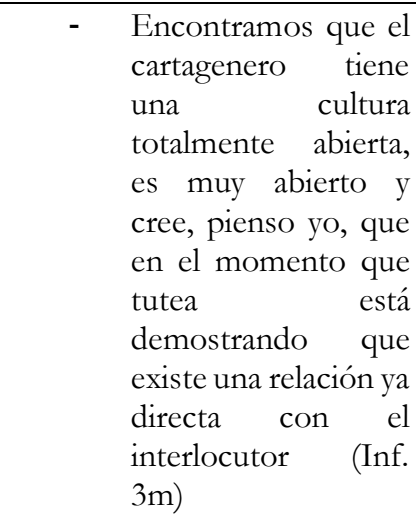 \\
\hline \multicolumn{3}{|c|}{ SANCIÓN SOCIAL } \\
\hline & Ejemplo positivo & Ejemplo negativo \\
\hline Veracidad & $\begin{array}{l}\text { Encontramos que el } \\
\text { cartagenero tiene una } \\
\text { cultura totalmente abierta, } \\
\text { es muy abierto8Inf. } 3 \mathrm{~m} \text { ) }\end{array}$ & $\begin{array}{l}\text { - Yo veo eso como } \\
\text { bien raro, porque yo } \\
\text { creo que uno tiene } \\
\text { como que estar } \\
\text { definido, si tiene } \\
\text { confianza con la } \\
\text { persona, el grado de } \\
\text { intimidad, todo lo } \\
\text { que permita que le } \\
\text { digas tú (Inf. 2f) } \\
\text { - Con x me siento rara }\end{array}$ \\
\hline Integridad Moral & $\begin{array}{l}\text { - No recuerdo bien. Igual, } \\
\text { cuando alguien me dice } \\
\text { usted, yo le digo dime tú; } \\
\text { porque si no me siento } \\
\text { vieja. (Inf. } 4 \mathrm{f} \text { ) }\end{array}$ & 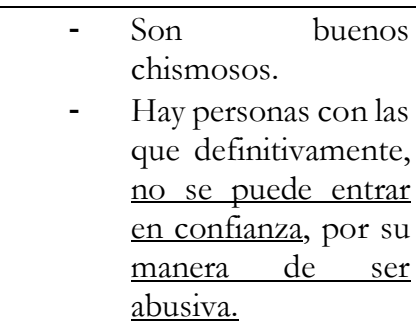 \\
\hline
\end{tabular}




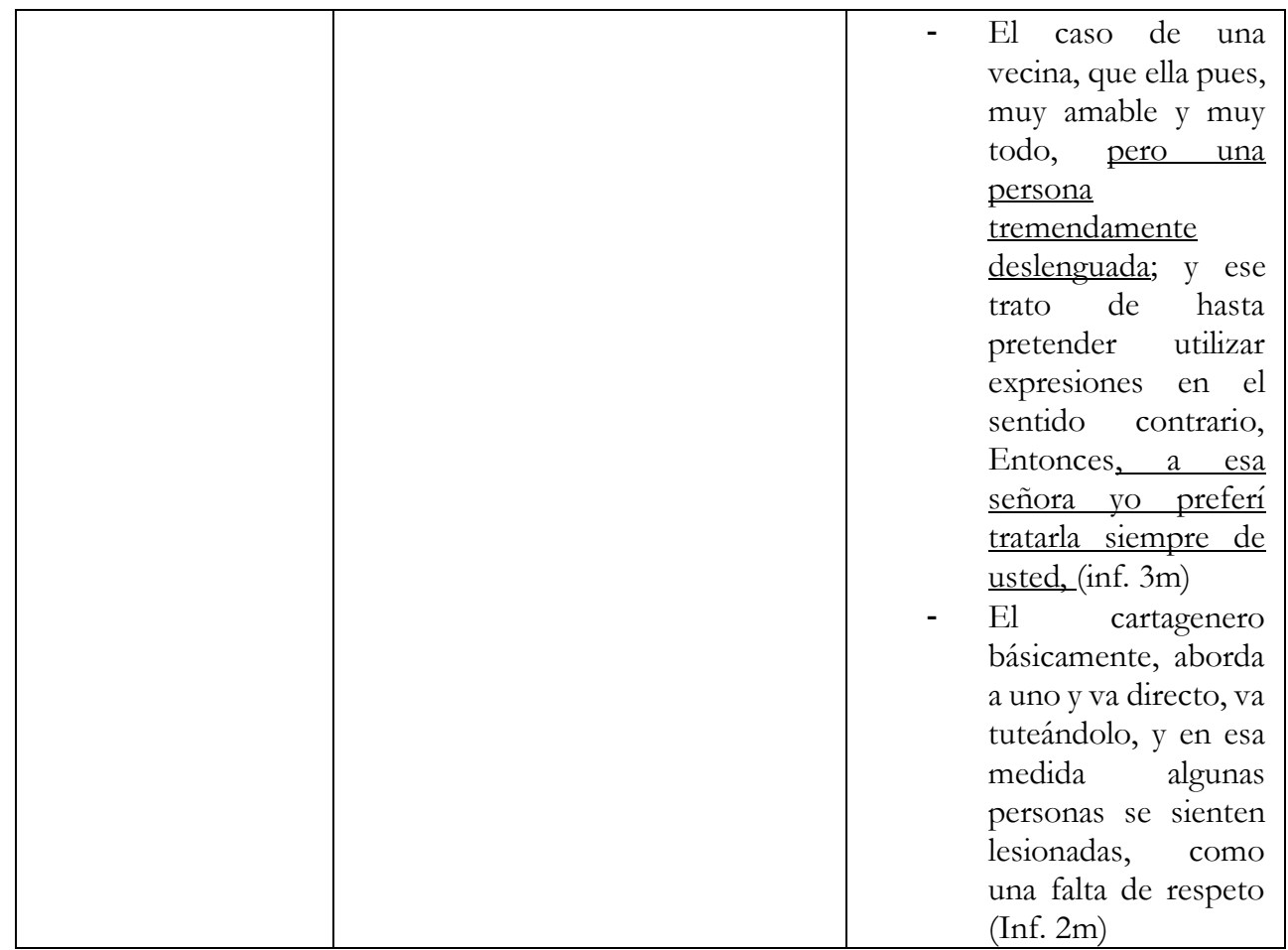

Tabla 2. Fuente: Investigadora

\begin{tabular}{|c|c|c|}
\hline \multicolumn{3}{|c|}{ APRECIACIÓN SOBRE EL USO DE LAS FORMAS DE TRATAMIENTO } \\
\hline & Positiva & Negativa \\
\hline $\begin{array}{l}\text { REACCIÓN } \\
\text { Impacto }\end{array}$ & $\begin{array}{l}\text { - Yo que creo que en } \\
\text { cualquier momento } \\
\text { de la comunicación } \\
\text { hay un impacto } \\
\text { psicológico. } \\
\text { - No quiero que se } \\
\text { tomen el derecho de } \\
\text { también tutearme }\end{array}$ & $\begin{array}{l}\text { - Yo la veo desde el } \\
\text { punto de vista de } \\
\text { relaciones sociales; } \\
\text { distante, o sea, no } \\
\text { tengo mucha } \\
\text { confianza con ella. } \\
\text { El tratarla de usted } \\
\text { es ponerle un freno }\end{array}$ \\
\hline $\begin{array}{l}\text { REACCIÓN } \\
\text { Calidad }\end{array}$ & $\begin{array}{l}\text { - La educación, el } \\
\text { hábito, no sé. Igual } \\
\text { esas son cosas que se } \\
\text { enseñan. }\end{array}$ & $\begin{array}{l}\text { - } \quad \text { Confianzuda } \\
\text { - } \quad \text { Yo la veo desde el } \\
\text { punto de vista de } \\
\text { relaciones sociales; } \\
\text { distante, o sea, no } \\
\text { tengo mucha } \\
\text { confianza con ella }\end{array}$ \\
\hline $\begin{array}{l}\text { COMPOSICIÓN } \\
\text { Balance }\end{array}$ & $\begin{array}{l}\text { Dentro de mi } \\
\text { experiencia familiar, } \\
\text { el tú es la norma (inf. } \\
4 \mathrm{~m})\end{array}$ & $\begin{array}{l}\text {...Entonces es mejor limitar } \\
\text { la conversación del taxista; }\end{array}$ \\
\hline $\begin{array}{l}\text { COMPOSICIÓN } \\
\text { Complejidad }\end{array}$ & $\begin{array}{l}\text { - yo siento que la } \\
\text { comunicación es un } \\
\text { asunto de carácter } \\
\text { personal }\end{array}$ & \\
\hline
\end{tabular}

Tabla 3. Fuente: Investigadora 
Fundamentando teóricamente las actitudes de los hablantes, encontramos una correspondencia: simetría; uso del Tú, asimetría; uso del usted. Desde los ejes que determinan la Distancia Social. Se explica la relación superior/inferior así: El eje horizontal, que para Oreichioni (1996) corresponde a estar en una misma condición dada, para nuestra muestra es si se trata de una persona del mismo estrato social (Como afirma Informante 2f), si son compañeros de trabajo o amigos (informante $3 \mathrm{~m}, 1 \mathrm{~m}, 2 \mathrm{f})$, o si tienen la misma edad. Mientras que el eje vertical lo representan no sólo los jefes sino las personas de mayor edad (para el caso del informante $2 \mathrm{~m}, 2 \mathrm{f}$, $1 \mathrm{~m})$.

Para Escandell (2006) "La distancia social es la relación entre los interlocutores (E $\mathrm{D}$, y en consecuencia, D- E) tal y como la configuran los patrones sociales vigentes en cada cultura" (p.183). Cuando se escucha distancia, suele equipararse a lejos, pero en realidad el criterio de distancia social establece relaciones cercanas y lejanas dependiendo el eje en que se esté revisando la relación. Veamos en el siguiente cuadro cómo se manifiesta esta categoría en la red Social estudiada

\begin{tabular}{|c|c|c|}
\hline Distancia social & Relación & $\begin{array}{l}\text { Forma pronominal más } \\
\text { usada }\end{array}$ \\
\hline $\begin{array}{l}\text { Simetría y solidaridad, } \\
\text { Brown y Gilman, 1960; Eje } \\
\text { de familiaridad, Escandell, } \\
2003 \text {, Eje Horizontal, } \\
\text { Oreichioni, 1996. }\end{array}$ & $\begin{array}{l}\text { Amigos, Compañeros de } \\
\text { trabajo, igual edad, igual } \\
\text { estrato social }\end{array}$ & Tú \\
\hline $\begin{array}{l}\text { Asimetría y poder, Brown y } \\
\text { Gilman, 1960; Eje de } \\
\text { Jerarquía, Escandell, 2003, } \\
\text { Eje Vertical Oreichioni, 1996 }\end{array}$ & $\begin{array}{l}\text { Jefes, personas de mayor } \\
\text { edad }\end{array}$ & Usted \\
\hline
\end{tabular}

Fuente: Investigadora

Sobresalen las relaciones enunciadas anteriormente con $60 \%$ (Conocido/Desconocido, Subalterno/Superior y Cercanía/lejanía) Sin embargo, se puede evidenciar cómo para el 30\% de los docentes influye la cultura. Por ejemplo; cuando la informante $3 \mathrm{f}$ dice "prefiero siempre el tú al usted, sobre todo en el contexto costeño caribeño", se puede inferir que se tiene una concepción de que la forma particular usada en la costa, en el caribe es el tú. No precisa estrato, relación social o jerarquía sino una influencia más bien de lugar. Una mirada desde lo cultural también se evidencia en el informante $3 \mathrm{~m}$, sin embargo, se identifica una estigmatización hacia el costeño y/o del cartagenero: "encontramos que el cartagenero tiene una cultura totalmente abierta, es muy abierto y cree, pienso yo, que en el momento que tutea está demostrando que existe una relación ya directa con el interlocutor." Esta frase no se precisa como discriminatoria, pero lo que sigue: "estaríamos diciendo que la confianza, es muy confianzudo, y en esa confianza, incluso, se puede llegar como a una falta de respeto, cuando tratan de tú"; sería otro ejemplo para lo que se exponía en la introducción de este trabajo; estigmatización del habla costeña que muchas veces es concebida así por el propio costeño o cartagenero.

Sobre lo descrito en el párrafo anterior, se puede leer literalmente en otro fragmento del informante $3 \mathrm{~m}$; "En otras partes del país, el vendedor es muy discreto con el cliente, con el posible cliente, aquí no. Aquí el vendedor aborda a uno; el cartagenero 
básicamente, aborda a uno y va directo, va tuteándolo, y en esa medida algunas personas se sienten lesionadas, como una falta de respeto". Revisando estas y otras expresiones se evidencia que "el abuso del cartagenero" se reduce al otro (incluso inferior, en este caso del informante, o al menos así lo ven) al mecánico, al taxista, al vendedor. Se infiere una nueva categorización en términos de oficio, nivel educativo, por ejemplo, estratificación social inferior. Mientras que, si lo hacen otros hablantes con nivel educativo superior, oficio más tradicional, estratificación alta; "suele ser normal tratar de tú sin miramientos de confianza o cercanía".

Para el 30\% de la red estudiada el uso del tú es abuso de confianza; lo vemos en el ejemplo anterior o cuando el informante $1 \mathrm{~m}$ habla de "liso" para quien trata de tú cuando no conoce al otro. La palabra liso en el habla cartagenera, se refiere a una persona que sobrepasa los límites de la confianza. Si se lee con cuidado muchos de los enunciados aquí presentados, notamos que el abuso, la descortesía siempre es departe del otro (a veces sin importar quien sea o casi siempre si es más joven, si no es de su círculo de amigos o de sí mismo estrato).

Informantes como el $4 \mathrm{~m}$ y $3 \mathrm{~m}$ (representan el $20 \%$ de la muestra) consideran que la forma de tratamiento debe enseñarse en casa. Pero antes, el mismo informante ratifica cómo la interacción social es determinante. Insiste que usar mucho usted crea una barrera; se ratifica el tú como cercanía y usted como lejanía en cuanto a las relaciones del Emisor y el Destinatario, y otras veces hasta se establece en término de Respeto/irrespeto: "yo soy muy respetuoso, básicamente, lo hago siempre tratando de usted a las personas desconocidas" (informante $3 \mathrm{~m}$ ).

Desde la misma percepción de los hablantes; de cómo ven ellos, el uso de las formas de tratamiento, podemos resaltar que el mayor marcador o determinante del uso de una de las dos formas es la Distancia Social dada por los ejes vertical y Horizontal. Desde esta interpretación, se refuerzan los conceptos de semántica de Poder y de solidaridad de Brown y Gilman (1960) y notamos cómo los informantes deciden cambiar de tú o usted al tratar a otra persona, pero algunos si no les devuelven el trato expresan un acto exhortativo otras veces directivos para ser tratado de una forma. Ejemplo: Relación con el vendedor o con el taxista. Se les debe decir usted para "que no falten al respeto". Se evidencia también que cuando el emisor siente amenazada su imagen con la forma de tratamiento de un destinatario, al que su conocimiento adquirido no lo asocia en su mismo estatus, se expresa con la forma de tratamiento que espera recibir veamos el siguiente fragmento:

"Fíjate en el caso de los taxistas, ocurre que los taxistas además de buenos conversadores, son buenos chismosos y buenos confesores, y utilizan el interrogatorio de una manera tan profunda y acuciosa, que es posible que uno termine sintiéndose contra la pared. Entonces, es mejor limitar la conversación del taxista; sobretodo, que nosotros en nuestro medio, encontramos que el taxista se mete en la conversación de los pasajeros, sin ningún reato de conciencia, sin ser invitado; van los pasajeros comentando y de pronto el taxista "mete su cucharada" sin que se le haya invitado a la conversación. Entonces es una manera de, como te digo, cortar la relación, no es un asunto de escala social o de escala de orden jerárquico, no, no no, en ningún momento, es una cuestión de orden personal." 
La frase final del fragmento evidencia que el emisor siente amenazada su imagen positiva por eso reitera con una secuencia de no que no se trata de jerarquías determinadas por rangos o estatus. Sin embargo, su tono inicial, su temor latente a ser considerado excluyente hace inferir aún más que si se trata de una distancia social motivada por la no familiaridad con su destinatario taxista, que depende además de no pertenecer al mismo grupo social.

\section{Conclusión y discusión}

Los resultados muestran que el contexto cognitivo, en términos de conocimiento adquirido, es decir, de lo que se comparte culturalmente entre un emisor y un destinatario, es determinante en la selección de una de las dos formas pronominales de tratamiento; tú o usted. Esta misma relación con la cultura, hace que no se establezcan reglas fijas sino siempre en correspondencia con el contexto cultural en el que el sujeto está inmerso. El valor de cognitivo hace que en cierta parte el conocimiento no sea sólo influido de afuera hacia adentro, sino que los procesos internos de la representación de los hablantes sea clave para interiorizar lo que el entorno le presenta.

Escandell (1998) sostiene que "la cortesía es un efecto que depende decisivamente de los supuestos previos que un individuo haya adquirido sobre cuál es el comportamiento socialmente adecuado" (p.15) esto es el conocimiento adquirido. Pero es importante precisar de dónde se obtiene o desde dónde está influido ese conocimiento; cultura propia, relación con otras culturas, grupos de contacto, entre otros. Algunos de nuestros informantes refuerzan las formas de tratamiento como si fuera una norma general "se debe tratar de usted a una persona mayor" de hecho así lo expresa Escandell (1998, p.15) cuando se refiere al español; que tiene dos formas de tratamiento tú y usted y que la primera se usa con personas de menor edad. Pero uno de nuestros casos es que el Docente, justamente, usa el usted con sus alumnos de menor edad para indicarles que así lo deben tratar o para limitarle la confianza. Lo que quiere decir que, si bien los ejes que representan la distancia social son determinantes en la forma de tratamiento, el contexto cognitivo influye considerablemente puesto que cuando la imagen positiva se ve amenazada con el uso del tú, el docente debe usar la forma que espera recibir de su destinatario; usted. Las normas de cortesía pretenden regular las formas de comportamiento y de tratamiento, pero decimos pretende porque notamos, para el caso de nuestro estudio, que no siempre se cumple; y no precisamente por una rebeldía de los estudiantes. El contrato conversacional como lo propone Oreichioni (1996) es también importante en el abordaje de este problema. Te digo tú para recibir tú; tú recíproco según Brown y Gilman (1960) o digo usted con igual sentido. Lo del contrato puede estar implícito; el emisor con una forma de tratamiento incita a su destinatario a que lo trate de la misma forma. Pero también puede ser explícito como la Inf. 2. F le expresa a una de sus compañeras: "anda, pero dime tú".

Este estudio permite tener un primer acercamiento con el fenómeno de las formas de tratamiento en Cartagena, por lo que sería importante ampliar la muestra e incluso trascender de la red a la población general de Cartagena. Sería un estudio que permitiría dar cuenta del problema y del tema en comparación con los estudios realizados en otras ciudades del país. Para ello se tendría en consideración un objetivo que permitiera comparar variables el cual sería contundente para conclusiones más precisas de la relación entre uso y género. 
Asimismo, para contribuir a aportar más a la teoría de Escandell sobre el conocimiento adquirido un estudio comparativo entre varias comunidades del mismo caribe colombiano porque suelen decir que los costeños, los caribeños usan más el tú, entre otros comentarios que quedan sin fundamento si no hacen parte de los resultados de una investigación.

Con la misma muestra habría sido pertinente también cruzar información como, por ejemplo; si las mujeres tienen un uso más común del pronombre tú que los hombres. Es decir, en este estudio es más constante el uso de tú recíproco de las mujeres indistintamente del destinatario, sin embargo, los hombres de la muestra tienen más variación en el uso de los pronombres.

La variable etaria también sería pertinente revisarla en una escala mayor en la población puesto que entre la muestra de este estudio sí había diferencias de edades que podría decirse influía en las categorías de estudio; Distancia Social y Contexto cognitivo.

\section{REFERENCIAS BIBLIOGRÁFICAS}

Baker, C. (1993). Attitudes and Language. Clevedon: Multilingual Matters. Journal Language and Society, (22), 559-564

Brown y Gilman. (1960) "The pronouns of power and solidarity" Sociolinguistics: The essential readings. (34) 475-512. DOI: 10.10170S0047404505210114

Duranti, A. (2004). A companion to Linguistic Anthroplogy. Oxford: Blackwell.

Duranti, A. (2000). Antropología Lingüistica. Madrid: Cambridge University Press.

Escandell, M (1998). Cortesía y Relevancia. En: La pragmática Lingüistica del español: recientes desarrollos. Diálogos Hispánicos, (22), 7-23

Escandell, M. (2006). Aportaciones de la Pragmática. En Sánchez, J. y Santos, I, $V$ ademécum para la formación de profesores. Enseñar español como segunda lengua y lengua extranjera (LE), (pp.179-197). Madrid: Sociedad General Española de Librería, SGEL.

Fagua Rincón, D., \& Padilla Torres, D. (2019). Propuesta para un diagnóstico sociolingüístico de poblaciones minorizadas en Cartagena : aproximación a su diversidad lingüistica $y$ sociocultural. VISITAS Al PATIO, 13(1), 61-80. https://doi.org/10.32997/2027-0585-vol.0-num.13-2019-2315

Hernández, J. (2004). El fenómeno de las actitudes y su medición en sociolingüística. Revista de estudios Filológicos, (8), 29-56.

Kaplan, N. (2004). Nuevos desarrollos en el estudio de la evaluación en el lenguaje: La teoría de la Valoración. Revista Boletín de Lingüistica, (2), 52-78.

Kerbrat-Orecchioni, C. (1996). La conversation. París: Seuil. 